\title{
Inspecionando a escola e velando pela saúde das crianças
}

\section{Inspecting the school and guarding the health of children}

\author{
Heloísa Helena Pimenta Rocha *
}

\begin{abstract}
RESUMO
Este artigo pretende analisar algumas das estratégias acionadas pelos médicos-higienistas, entre o final do século XIX e as décadas iniciais do XX, com vistas a produzir uma nova configuração para a escola e, ao mesmo tempo, novos dispositivos de organização do trabalho pedagógico. Para tanto, toma como fontes os livros A hygiene na escola (1902) e Hygiene escolar e pedagogica (1917), de autoria do Dr. Balthazar Vieira de Mello, produzidos em diferentes momentos da atuação profissional desse médico-higienista, em sua militância pela institucionalização da inspeção médica das escolas paulistas.

Palavras-chave: história da educação, inspeção médica escolar, cultura escolar.
\end{abstract}

\begin{abstract}
This article intends to analyze some of the strategies implemented by physician-hygienists between the end of 19th Century and the first decades of the 20th Century. The analysis aims to produce a new shape for the school and, at the same time, new devices to organize the pedagogical work. Therefore, this study was based on the the books A hygiene na escola (Hygiene in the school, 1902) and Hygiene escolar e pedagogica (Scholar and pedagogic hygiene,1917). These publications were written by Dr. Balthazar Vieira de Mello, who made the effort to institutionalize

* Doutora em Educação (USP). Professora na Faculdade de Educação da Universidade Estadual de Campinas (Unicamp). E-mail: heloisah@unicamp.br
\end{abstract}


the medical inspection at schools in São Paulo State, during different moments of his professional performance as a physician-hygienist.

Key-words: history of education, medical inspection of schools, scholar culture.

Produzir um espaço próprio para as práticas pedagógicas, redefinir o emprego do tempo, adequar os móveis e materiais escolares às dimensões do corpo infantil, conformar os métodos e processos de ensino aos padrões higiênicos, elaborar dispositivos de normalização, com vistas a prevenir e corrigir as deformidades físicas e intelectuais das crianças, assegurando-lhes a saúde plena. Estas foram algumas das preocupações que se impuseram aos médicos-higienistas brasileiros, em sintonia com o movimento higienista que ganhava corpo internacionalmente, entre a segunda metade do século XIX e as décadas iniciais do XX. Preocupações essas que podem ser observadas quando se analisam as iniciativas que redundaram na criação da Inspeção Médica Escolar (IME) em São Paulo.

Tomando como fontes dois livros de autoria do Dr. Balthazar Vieira de Mello, produzidos em diferentes momentos da atuação desse profissional, em sua militância pela institucionalização da inspeção médica das escolas paulistas, este artigo busca analisar algumas das estratégias acionadas pelos médicos-higienistas com vistas a produzir uma nova configuração para a escola e, ao mesmo tempo, novos dispositivos de organização do trabalho pedagógico. ${ }^{1}$

Trata-se dos livros A hygiene na escola $(1902)^{2}$ e Hygiene escolar $e$ pedagogica (1917). ${ }^{3}$ O primeiro, produzido em um momento em que o Dr. Vieira de Mello atuava como inspetor sanitário, vinculado ao Serviço Sanitário de São Paulo, acumulando já uma significativa experiência no combate às epidemias que grassavam no interior do Estado; o segundo, elaborado quando da transferência da IME, do Serviço Sanitário para a Diretoria Geral da Instrução Pública. Produzidos em circunstâncias distintas, esses dois livros

1 Uma versão deste artigo foi apresentada no V Congresso Luso-brasileiro de História da Educação, realizado na Universidade de Évora, em abril de 2004, com apoio do Faep/Unicamp.

2 MELLO, Balthazar V. A hygiene na escola. São Paulo: Typographia do Diario Official, 1902.

3 MELLO, Balthazar V. Hygiene escolar e pedagogica para uso de medicos, educadores e estabelecimentos de ensino. São Paulo: Casa Vanorden, 1917. 
tinham como objetivo redesenhar a instituição escolar, em seus mais diversos aspectos, submetendo-a aos cânones da higiene.

\section{Em defesa da vigilância higiênica das escolas}

Instituída em 1911, pelo Decreto n. 2.141, como repartição do Serviço Sanitário de São Paulo, e transferida mais tarde, pela Lei 1.541, de dezembro de 1916, para a Diretoria Geral da Instrução Pública, a IME teve na figura do Dr. Balthazar Vieira de Mello seu grande paladino. Assumindo a direção do órgão por um largo período e resistindo, inclusive, à mudança de jurisdição, Dr. Vieira de Mello foi o profissional em cujas mãos o governo do Estado depositou, ainda em 1902, a responsabilidade pela produção de uma obra que, certamente, forneceu as linhas mestras que orientaram a implantação da inspeção médica das escolas em São Paulo. ${ }^{4}$

Publicada com a autorização e sob os auspícios do governo do Estado de São Paulo, ${ }^{5}$ por um profissional pertencente aos quadros do Serviço Sanitário, ${ }^{6}$ A Hygiene na escola deve ser lida no contexto das estratégias de inter-

4 Alguns aspectos da produção da obra $A$ hygiene na escola e do tratamento conferido pelo autor à educação escolar foram tematizados no artigo ROCHA, H. H. P.; GONDRA, J. G. A escola e a produção de sujeitos higienizados. Perspectiva, v. 20, n. 2, p. 493-512, jul./dez. 2002.

5 Não é demasiado supor que o livro foi encomendado ao Dr. Vieira de Mello pelo governo do Estado de São Paulo. Os vínculos do autor com as altas esferas da administração paulista ficam evidentes na dedicatória a Bernardino de Campos, presidente do Estado, entre 1892 e 1896, e a Bento Bueno, secretário dos Negócios do Interior e Justiça, à época da publicação da obra, bem como nos agradecimentos: ao primeiro, pelos seus feitos em matéria de higiene e instrução pública; a Bento Bueno, por haver autorizado a publicação, e a Emílio Ribas, diretor do Serviço Sanitário, a quem o autor agradece pelo interesse que manifestou em relação à publicação do livro. Além desses indícios, encontramos, no prefácio, um trecho que parece confirmar que a elaboração do livro resultara de uma encomenda: "procurando honrar a incumbencia que nos foi commettida, haurimos em fontes que nos pareceram mais puras os ensinamentos mais uteis e os transmitimos em linguagem despida de pretenções, de modo a sermos comprehendido pela intelligencia o menos preparada no assumpto, como se faz mistér em trabalhos da natureza deste" (MELLO, 1902, p. v-vi).

6 À época da publicação dessa obra, Dr. Vieira de Mello era inspetor sanitário do Serviço Sanitário de São Paulo, tendo atuado como diretor de hospitais em várias epidemias, cabendo registrar que, em 1895, foi comissionado em São Carlos, durante a epidemia de febre amarela. Sócio benemérito da Policlínica Geral do Rio de Janeiro e membro correspondente do Círculo 
venção dos médicos-higienistas sobre a instituição escolar. Estratégias essas que se materializaram, dentre outras formas, por meio da publicação, nas primeiras décadas do século XX, de uma literatura voltada para a prescrição de modos de conduta para professores e alunos, como também de modelos para a organização da instituição escolar (ROCHA; GONDRA, 2000). Constituindo como interlocutores os educadores e as autoridades, os médicos-higienistas procuraram, por intermédio dessas estratégias, convencê-los da necessidade e da urgência das medidas prescritas, oferecendo-lhes, ao mesmo tempo, um roteiro para a conformação da escola aos imperativos da higiene.

Considerado por Lima (1985), no estudo que empreende sobre a constituição do campo da saúde escolar no Brasil, como um trabalho pioneiro, tanto pela sua amplitude como pela organização, o livro compõe-se de prefácio, oito capítulos, um apêndice sobre inspeção médica escolar, seguido das conclusões. Os seis capítulos iniciais tratam de questões que se referem ao meio escolar e à organização do trabalho pedagógico; nos dois capítulos seguintes, o autor aborda as moléstias, classificando-as naquelas que são adquiridas na escola e as que se propagam nesse meio. Como corolário do estudo, o apêndice enuncia a necessidade de inspeção médica periódica das escolas públicas. Nas conclusões, o autor reafirma, de modo resumido, as suas posições em relação aos temas tratados. ${ }^{7}$

Apresentando os objetivos visados pela obra, Dr. Vieira de Mello a define como um trabalho de propaganda, comprometido com a divulgação de noções práticas de higiene escolar entre os responsáveis pelo desenvolvimento intelectual e físico da infância e mocidade, consideradas pelo autor como "legitimos depositarios da força activa e defensiva da Patria" (MELLo, 1902, p.

Médico Argentino de Buenos Aires, era redator do Annual of the Universal Medical Sciences, da Filadélfia, e já havia sido redator da União Médica, do Rio de Janeiro, entre 1882 e 1890. Registrando a trajetória profissional do Dr. Vieira de Mello, Lima anota que ele era "proprietário da revista Imprensa Médica, na qual mantinha uma seção sobre medicina social, fundou as Clínicas Dentárias Escolares em 1912, que depois dariam a Associação Paulista de Assistência Escolar e seria o primeiro diretor da Inspetoria Médica Escolar de São Paulo” (LIMA, 1985, p. 107-108).

${ }^{7}$ Para se ter uma idéia mais clara da estrutura da obra, reproduzimos os títulos dos capítulos: Capítulo I - Situação e construcção do edificio escolar; Capítulo II - Ventilação, illuminação e limpeza; Capítulo III - A mobilia escolar e o material de ensino; Capítulo IV - Posições e attitudes escolares; Capítulo V - Methodos e processos de ensino; Capítulo VI - Distribuição das materias - Horas de classe e de recreio - Exercicios physicos - Gymnastica; Capítulo VII Molestias que se adquirem no meio escolar; Capítulo VIII - Moléstias que se propagam no meio escolar; Appendice - Inspecção medica escolar - Medidas hygienicas e administrativas; Conclusões. 
vii). A obra, entretanto, não cumpre apenas a função de difusão dos preceitos higiênicos, de modo a colocá-los à altura daqueles que, envolvidos com a educação das crianças e jovens, viessem a se interessar pelo assunto. A seleção dos temas, a sua organização e o diálogo que estabelece com o leitor se articulam no sentido de afirmar a necessidade e urgência da vigilância higiênica da escola, nos seus mais diferentes aspectos - desde a localização do edifício escolar até o emprego do tempo e a escolha dos métodos e processos de ensino - e, ao mesmo tempo, de oferecer um modelo de organização a ser seguido pelas escolas primárias (ROCHA; GONDRA, 2002). Nesse empreendimento, ao Estado é atribuído um papel central, já que a ele, segundo afirma o autor, "compete velar pela saude das creanças, preparando-lhes mocidade florescente, afim de augmentar o bem estar geral, a força activa e a força defensiva da nação" (MELLO, 1902, p. vii).

Espaço, tempo, mobiliário, material escolar, métodos e processos de ensino, exercícios físicos e ginástica, escrita e leitura, considerados sob o ponto de vista da adequação aos preceitos higiênicos, constituem-se em algumas das questões abordadas. A discussão sobre a dimensão espacial, inspirada na legislação austríaca, incide sobre a localização e construção do edifício escolar, ventilação, iluminação e limpeza. Distinguindo a escola das habitações, no que se refere aos preceitos sanitários que deveriam ser observados na sua construção, o autor destaca o valor de um "plano inteligente e prático", em que fossem levadas em conta: a localização da escola e as suas vizinhanças; a disposição das salas de aula, refeitório, aparelhos sanitários, pátios para recreio; as dimensões do edifício, da sala de aula e das demais instalações; a circulação do ar e da água; a iluminação.

Participando da constituição da escola como um lugar de ensino, o discurso médico-higienista define uma localização para a escola na cidade, propõe modos de organização do espaço escolar e, ao mesmo tempo, procura instituir uma dimensão educativa para esse espaço. Quanto à localização da escola, as inúmeras interdições enunciadas visam produzir um afastamento em relação às fábricas, oficinas, igrejas, estações de trem, quartéis, prisões, hospitais, cemitérios, estábulos e cocheiras. Distante dos ruídos e das exalações, do mundo do trabalho, da doença e da morte, a escola vai sendo pensada enquanto lugar de silêncio, atenção e, sobretudo, enquanto lugar de saúde.

O mobiliário escolar - considerado do ponto de vista das dimensões e disposição do banco, da distância entre o banco e a mesa para os exercícios de leitura e escrita, da largura e inclinação da mesa - é tratado no mesmo capítulo que os materiais de ensino, atribuindo-lhes o autor igual nível de importância: "Dê-se á creança excellente mobilia escolar e máu material de ensino, e 
as vantagens da primeira serão derogadas pelo segundo" (MELLO, 1902, p. 20). A proporcionalidade entre a estatura da criança e o mobiliário e, por outro lado, a adequação entre os materiais de ensino e os alunos de uma mesma classe parecem traduzir-se, no conjunto da obra, numa só e mesma preocupação: a de repensar a escola e os objetivos do trabalho pedagógico em função das características infantis e, ao mesmo tempo, de modelar o corpo e a "alma" da criança por meio da ação da escola. "Assim, os livros, cadernos, lousas, lapis, canetas e pennas, cartas geographicas, globos terrestres e quadros, tudo, enfim, quanto constitue o material de ensino deve ser cuidadosamente escolhido pelo educador, na conformidade dos elementos da classe a seu cargo" (MELLO, 1902, p. 20).

Aos educadores não deveria parecer estranha a intervenção da higiene, mesmo em relação a questões que mais tarde passarão a ser consideradas de natureza eminentemente pedagógica, cabendo antes repensar o seu trabalho em função dos preceitos higiênicos, na medida em que, da articulação entre higiene e educação, resultaria o equilíbrio entre o desenvolvimento físico e intelectual dos alunos. Posição essa que se expressa, com clareza meridiana, nas seguintes afirmações:

Tudo na escola deve obedecer a um plano em que a hygiene e a pedagogia se dêem as mãos para o cabal desenvolvimento intellectual e physico da infancia e da mocidade. (MELLO, 1902, p. 21)

Por mais que á pedagogia possa parecer estranha a intervenção da hygiene neste assumpto, não se póde contestar a sua influencia sobre os methodos de ensino, porquanto estes actuam em alto grau sobre o desenvolvimento physico e a saude intellectual da creança. (MELLO, 1902, p. 29)

Nesse sentido, os métodos e processos de ensino também se constituiriam em objeto da atenção dos médicos-higienistas, sendo possível esperar, como resultado dessa associação entre higiene e pedagogia, a articulação de um trabalho pedagógico eficiente, já que calcado nas leis da ciência. Trabalho esse que resultaria no pleno desenvolvimento infantil: "De facto, as faculdades intellectuaes e physicas da creança só podem ser harmonicamente desenvolvidas, se o educador basear o seu methodo de ensino nas leis que regem o crescimento, procurando concurrentemente desenvolver todas ellas, com especialidade os sentidos, a vontade e a sensibilidade" (MELLO, 1902, p. 29).

A higienização da leitura e da escrita figuram como aspectos centrais na discussão sobre métodos e processos de ensino. O desenvolvimento dos sen- 
tidos, vontade, sensibilidade e capacidade de reflexão adquirem especial relevo na análise dos métodos de ensino da leitura. Merecem registro, ainda, as prescrições em relação à escolha dos livros, as quais se inserem num movimento de constituição da boa leitura e, por oposição, da leitura perniciosa, evidenciando os intentos de conformação dessa prática aos cânones da higiene. No que se refere à higiene da escrita, a natureza da letra assume um lugar central, recomendando-se a letra direita pelo fato de gerar menos prejuízos à saúde do aluno, aliada às vantagens que apresentava do ponto de vista da rapidez, elegância e clareza. A discussão sobre as posições e atitudes dos alunos, sobretudo durante os exercícios gráficos, põe em cena o papel que deveria exercer o educador no que se refere à prevenção e correção das posturas inadequadas ou, em outras palavras, das atitudes viciosas (ROCHA; GONDRA, 2002).

As prescrições que se referem aos métodos e processos de ensino evidenciam os objetivos de rapidez, eficiência e produtividade que deveriam perpassar o trabalho pedagógico e, nessa medida, indicam a preocupação com a constituição da escola na sua dimensão temporal. Entretanto, é na discussão sobre o programa de ensino e a distribuição das matérias que essa preocupação se articula mais claramente. Horas de estudo e horas de recreio, número de matérias e sua distribuição, dimensões do programa, sedentarismo, surmenage e exercícios físicos são alguns dos aspectos em torno dos quais se articula essa discussão sobre a segmentação e o emprego do tempo escolar, na qual o grau de atenção do aluno figura como medida:

Quanto maior numero de materias abrange um programa de ensino, tanto menos se desenvolve a intelligencia do alumno, tanto mais se sacrifica sua saude cerebral.

Esta proposição, calcada nos sãos principios da physiologia e da hygiene, devia servir de base á distribuição das materias escolares. (MELLO, 1902, p. 34)

No roteiro de leitura que vai propondo ao longo da obra, Dr. Vieira de Mello destaca o capítulo que versa sobre as moléstias adquiridas no meio escolar como o mais importante, aquele que sintetiza as discussões sobre a higiene da escola. Pondo em destaque os problemas decorrentes da negligência em relação às prescrições enunciadas nos capítulos anteriores, quanto ao edifício, mobiliário, programas, métodos, processos e materiais de ensino, $\mathrm{o}$ autor procura estabelecer a justa medida entre a escola e o aluno, de modo a 
evitar que a freqüência a essa instituição se configurasse em obstáculo ao desenvolvimento físico e intelectual das crianças e jovens (ROCHA; GONDRA, 2002).

Um aspecto para o qual vale a pena atentar, nesse capítulo, é o que diz respeito às posições e atitudes das crianças, as quais são analisadas na sua correlação com o meio escolar. Assim, referindo-se à miopia, aos desvios da coluna vertebral e às moléstias da nutrição ${ }^{8}$ enquanto "moléstias propriamente escolares", o autor considera, como a sua principal causa, os vícios e defeitos das instalações, bem como dos materiais, programas, métodos e processos de ensino. Corrigir as deformidades e, mais que isso, evitar que alunos e alunas adquirissem atitudes viciosas deveria constituir-se numa preocupação fundamental da escola, em função da qual educadores e médicos-higienistas deveriam se unir.

A manutenção de uma postura adequada durante os exercícios de leitura e escrita e os cuidados com iluminação, mobiliário, qualidade da impressão dos livros e materiais escolares são algumas das preocupações que perpassam o capítulo, traduzindo-se em prescrições sobre a postura correta a ser assumida durante os trabalhos escolares e ilustrações das posturas corretas, das atitudes viciosas e das deformidades. No intuito de corrigir e evitar as deformidades, aos educadores cabia o dever de cuidar do alinhamento do corpo dos alunos e alunas em relação a carteira, mesa, papel, livros, sobretudo durante a escrita:

Dahi a necessidade de se manter o alumno em attitude recta e conservar o papel direito, em posição mediana.

Deste modo a lettra será necessariamente direita, a cabeça se conservará direita, o corpo e a columna vertebral direitos, satisfazendo a lei que celebre escriptora condensou nesta formula egualmente celebre:

"Lettra direita, papel direito, corpo direito". (MELLO, 1902, p. 51)

O conjunto de prescrições enunciadas pelo Dr. Vieira de Mello visa organizar a escola tomando o corpo e a "alma" dos alunos como medida e, ao mesmo tempo, modelá-los a partir da ação do meio escolar, prevenindo e corrigindo as deformidades. Por intermédio de práticas discursivas que con-

${ }^{8}$ Dentre as moléstias da nutrição figuram os problemas gastro-intestinais, respiratórios, de locomoção, dos dentes e do cérebro, merecendo destaque, dentre os últimos, a surmenage, estado de esgotamento que era atribuído ao excesso de trabalho intelectual imposto às crianças. 
figuram o meio escolar como gerador de deformidades, na medida em que não eram respeitadas as recomendações em relação ao edifício, mobiliário, divisão do tempo, métodos e processos de ensino, o autor vai construindo os argumentos que justificam a necessidade da vigilância higiênica da escola e dos alunos. Enquanto proposição básica, pode-se identificar a defesa da urgência de produção de uma nova espacialidade e uma nova temporalidade escolar, subjacente à qual, encontra-se a representação de um corpo moldável e do poder do meio externo nessa obra de modelagem (ROCHA; GONDRA, 2002).

A produção de um corpo forte e um espirito sadio, adaptado às necessidades do trabalho e da defesa da pátria, no caso dos meninos, e às exigências do "acto supremo da maternidade" (MELLO, 1902, p. 47), no caso das meninas, figura como intento em torno do qual se articulam as prescrições higiênicas que marcam a obra. Assim, o apêndice intitulado Inspecção Medica Escolar: medidas hygienicas e administrativas não ocupa um lugar secundário na estrutura da obra. Operando como uma espécie de conclusão, ele exerce um papel fundamental, na medida em que, a par das considerações em relação aos vários aspectos da organização escolar e com base no exemplo de países como Rússia, Áustria, Alemanha, Holanda, Bélgica, Suíça e Inglaterra, propõe ao Estado de São Paulo a criação da inspeção médica das escolas públicas.

Dentre as atribuições que deveriam caber a essa repartição que, em sua concepção, poderia se vincular ao Serviço Sanitário, estaria, além da inspeção das condições de salubridade do meio escolar, a vacinação e revacinação, o exame periódico dos alunos e a organização da estatística sanitária escolar, a qual se pautaria não apenas nos dados sobre as instalações escolares, como também em dados precisos sobre os alunos:

Nessas visitas, além das questões de hygiene e de salubridade, os alumnos seriam examinados e medidos anthropometricamente, consignando-se em boletins o estado de saude de cada um, a estatura, o peso, a circumferencia do peito e da cabeça, a capacidade pulmonar, o grau de força muscular, as lesões ou deformidades, o estado das funções visuaes, dos ouvidos e dos dentes, com a declaração dos exercicios physicos compativeis com a organisação individual e, em caso de necessidade, a interrupção ou suspensão dos trabalhos escolares. (MELLO, 1902, p. 68)

O exame físico dos escolares figura, ainda, como elemento central na prevenção à tuberculose, na medida em que permitiria acompanhar as altera- 
ções do desenvolvimento físico e intelectual, oferecendo subsídios para a definição da duração e intensidade do trabalho intelectual e dos exercícios físicos. A implantação da inspeção médica escolar se constituiria, desse modo, no coroamento da obra de institucionalização dos serviços de higiene em São Paulo, uma vez que possibilitaria estabelecer "nas escolas o exame methodico dos alumnos, a vigilancia incessante das alterações por que passam nas diversas phases do seu desenvolvimento intellectual e physico, graduando o trabalho que lhes deve ser distribuido, desenvolvendo-lhes as forças physicas, medindolhes os contornos para avaliar-lhes a inteligencia" (MELLO, 1902, p. 58).

A obra publicada pelo Dr. Vieira de Mello em 1902 possibilita uma aproximação das estratégias de intervenção por meio das quais os médicoshigienistas procuraram definir um modelo para a escola primária, calcado nos cânones da racionalidade científica, configurando-a enquanto instituição a serviço da obra de disciplinamento da infância. A importância desse livro pode ser melhor aquilatada quando se tem presente o seu lugar de produção, a sua circulação nas escolas primárias e, ainda, o cargo que o Dr. Vieira de Mello será chamado a assumir a partir de 1911, com a criação da Inspeção Médica Escolar. ${ }^{9}$ Vale lembrar, ainda, a sua continuidade à frente desse serviço, mesmo com a remodelação que transformou a IME em uma seção da Diretoria Geral da Instrução Pública, em 1916. ${ }^{10}$

\footnotetext{
${ }^{9}$ Não deve parecer casual, nesse sentido, a coincidência entre os temas abordados no livro e os artigos do Decreto n. 2.141, que conferiam à Inspeção Médica Escolar, dentre outras atribuições: "a indicação das medidas hygienicas e administrativas quanto à situação e construcção dos edificios escolares; a escolha (de accôrdo com a direcção da instrucção publica) do mobiliario escolar, dos methodos e processos de ensino, das posições e attitudes escolares, bem como a distribuição das materias de estudo, das horas de classes, dos recreios e dos exercicios physicos" (apud SILVA, 2001, p. 33). Para uma análise sobre a criação da Inspeção Médica Escolar em São Paulo, as atribuições a ela delegadas e as disputas de poder que responderam pela sua subordinação ora ao Serviço Sanitário, ora à Diretoria da Instrução Pública, cf. SILVA, A. C. G. Inspeção Médica Escolar em São Paulo (1911-1930): a escola como lugar de higiene e saúde. São Paulo, 2001. Dissertação (Mestrado em Educação: História, Política, Sociedade) - Pontifícia Universidade Católica de São Paulo.

${ }^{10}$ As disputas entre os médicos e os profissionais da educação, certamente, tiveram um importante papel nas mudanças de jurisdição pelas quais passou a IME. Vale registrar que a remodelação operada pela lei de 1916 é recebida com grande entusiasmo por Oscar Thompson, então diretor geral da Instrução Pública, que interpreta os novos rumos impressos à inspeção médica das escolas como conseqüência da difusão dos ideais escolanovistas. Em sua leitura, tal remodelação evidenciava que a saúde dos pequenos escolares já não podia ser tratada exclusivamente no campo das iniciativas de inspeção sanitária, mas passava a se configurar em uma questão pedagógica, nos marcos de uma proposta educacional que tomava a questão da saúde como um dos seus pilares. Sobre esta questão, cf. ROCHA, H. H. P. Do exame da criança à produção do aluno: notas sobre o estudo científico da infância. Revista Pedagógica, ano 6, n. 13, jul./dez. 2004.
} 


\section{A criança sob vigilância}

Investido da autoridade de médico-chefe da Inspeção Médica Escolar e municiado dos elementos oferecidos pela vasta experiência, que incluía os anos de atuação como inspetor sanitário no combate aos surtos epidêmicos, a fundação e direção da Assistência Escolar em São Paulo e os cinco anos respondendo pela direção da IME junto ao Serviço Sanitário, o Dr. Vieira de Mello publica, em 1917, o livro Hygiene escolar e pedagogica para uso de medicos, educadores e estabelecimentos de ensino. ${ }^{11}$ A obra é composta por um prefácio, um pequeno texto intitulado Hygiene escolar e pedagogica, reunindo informações sobre a reestruturação e mudança de jurisdição da IME, e seis capítulos. Publicação oficial da Inspeção Médica Escolar do Estado de São Paulo, o livro tem como intento sistematizar um conjunto de instruções, de modo a garantir a boa execução e uniformidade dos trabalhos de inspeção das escolas.

Concebido como um guia que deveria nortear a atuação dos médicos inspetores escolares, a grande maioria dos quais não pertencia aos quadros da IME, mas agregava às lides de inspetor sanitário o trabalho de inspeção das escolas públicas e particulares de ensino primário, normal, secundário e profissional, sob a direção e fiscalização do médico-chefe, o livro assume uma estrutura que procura favorecer a consulta em relação aos mais diferentes tópicos sobre os quais deveria se voltar a atenção desses profissionais, no desempenho da nova função que lhes era atribuída.

Dever de ofício cumprido com o mais devotado patriotismo, como assinala Dr. Vieira de Mello no prefácio, a elaboração do livro buscara na literatura internacional e nos regulamentos estrangeiros as bases sobre as quais se deveria organizar o trabalho desse corpo profissional, chamado a zelar pelo desenvolvimento intelectual e físico da infância, por meio da intervenção sobre a escola, concebida como "centro de irradiação de homens aptos a defende-la [a Pátria] e de mães compenetradas dos seus deveres sociaes" (MELLO, 1917, p. 8).

Marcado por esse intento de conformação das práticas dos médicos inspetores escolares, o livro assume uma feição bastante distinta da obra publicada

${ }^{11}$ Como seu primeiro livro, a obra é dedicada às altas autoridades - Altino Arantes, presidente do Estado e Oscar Rodrigues Alves, secretário do Interior - como reconhecimento pela capacidade administrativa e pelos feitos em favor da assistência escolar. 
em 1902. Além de um extenso e minucioso inventário das moléstias escolares, chama a atenção a centralidade que assume a questão do exame, medição e classificação das crianças; preocupação essa já esboçada na obra A Hygiene na escola, quando o Dr. Vieira de Mello defendia, como uma das atribuições da inspeção médica escolar, a organização da estatística sanitária, produzida com base nos dados sobre as instalações escolares, como também em dados sobre os alunos, levantados a partir dos exames antropométricos. ${ }^{12}$

As preocupações em relação ao edifício, mobiliário e materiais escolares, tratadas nos dois capítulos iniciais de Hygiene escolar e pedagogica, perdem a ênfase que mereceram na obra anterior. Tomando como referência o texto legal que reorganizou a IME e, mais especificamente, o artigo que dispõe sobre as competências do médico inspetor quanto à avaliação das plantas dos edifícios escolares, o autor examina, no primeiro capítulo, aspectos ligados ao "plano de situação", "planos de distribuição" e "planos de classes" das escolas e retoma as prescrições em relação aos móveis e materiais escolares enunciadas na obra de 1902.

Mantém-se, na abordagem dessas questões, a preocupação em evitar que a freqüência escolar fosse geradora de deformidades corporais, embora se observem variações na forma como alguns aspectos são tratados. Exemplar, nesse sentido, é a discussão sobre os efeitos da letra inclinada sobre a visão do aluno. Redimida em função da economia de tempo e esforço que representava, essa letra passa a ser recomendada, devendo os educadores estar atentos ao tempo de duração dos exercícios gráficos e à postura do aluno, de modo a evitar os possíveis desvios. $\mathrm{O}$ alinhamento entre a letra, o papel e o corpo infantil cede lugar, no primeiro capítulo, à possibilidade de inclinação da letra e de uma ligeira inclinação do papel, desde que respeitada a postura correta do corpo. Questão tratada de modo controverso, no âmbito da obra, na medida em que o capítulo sobre as moléstias escolares, reproduzindo algumas das orientações contidas na obra de 1902, reafirmará a preponderância da letra direita, invocando a máxima "Lettra direita, papel direito, corpo direito" (MELLO, 1917, p. 123).

${ }^{12}$ A estrutura do livro pode dar uma idéia mais clara dessa centralidade assumida pelas práticas de exame e classificação dos alunos: Prefacio, p. 7-9; Remodelação da Inspecção Medica Escolar, p. 11-12; Capítulo I - O edificio escolar - p. 13-36; Capítulo II - Internatos e collegios - p. 37-56; Capítulo III - Exame medico do escolar - p. 57-102; Capítulo IV - Classificação dos anormaes - p. 103-106; Capítulo V - As molestias escolares - p. 107-152; Capítulo VI - Médias do desenvolvimento physico dos escolares da cidade de S. Paulo - p. 153-175. Ao final, é publicado o texto da lei que reorganizou a IME. 
Na discussão sobre o "plano de situação" das escolas, o autor procura oferecer elementos para a escolha do local onde deveria ser construído o edifício escolar, considerando o solo, as relações de vizinhança, ${ }^{13}$ a orientação em relação à luz e aos ventos. A arquitetura escolar, envolvendo aspectos que vão do número de pavimentos até as dimensões e disposição de escadas, vestíbulos, corredores, pátios, ginásios e instalações sanitárias, é discutida no item "planos de distribuição". O item "plano de classes" aborda a forma e as dimensões das "salas de classes", consideradas sob o ponto de vista das exigências pedagógicas e higiênicas, que se traduzem na necessária vigilância sobre as crianças e nas adequadas condições de arejamento e iluminação para a realização dos trabalhos escolares.

A discussão sobre a localização, dimensões e distribuição interna do edifício escolar é retomada no segundo capítulo, que reúne um conjunto de prescrições que deveriam ser respeitadas na construção dos internatos e colégios, no que se refere a dormitórios, lavatórios, salas de banhos, refeitórios, cozinha, enfermaria. Tais prescrições põem acento no fato de que a vida em comum ali não se restringia a uma parte do dia, o que exigia uma atenção redobrada no sentido de garantir o afastamento do edifício das influências nocivas das aglomerações urbanas, assim como dos problemas de falta de arejamento, ventilação e iluminação. Perpassando essas prescrições, sobressai o cuidado com os riscos do desregramento moral que a convivência nessas instituições poderia favorecer; cuidado que se traduz em inúmeros dispositivos de vigilância atenta e permanente.

A higiene física, intelectual e moral dos colegiais é um outro eixo em que se desdobra esse capítulo, que contempla aspectos ligados ao sono, duração do trabalho intelectual, repouso, alimentação e atividade física dos internos. Ocupando lugar de destaque nas discussões sobre a higiene intelectual, figura a questão da fadiga cerebral, resultante de uma inadequada organização dos horários e programas escolares, elaborados, segundo o autor, em flagrante desrespeito à idade das crianças e às diferenças fisiológicas e psicológicas entre os sexos. Quanto às distinções entre meninos e meninas, que deveriam ser observadas na configuração das práticas escolares, destaca: "De facto, ao passo que no sexo masculino predomina o systema muscular, no

${ }^{13}$ As interdições em relação à vizinhança assumem, nesse livro, um caráter moral ainda pouco explicitado na obra anterior. Assim, o afastamento da escola dos espaços de aglomeração visava garantir não apenas o silêncio, a segurança e a defesa das crianças contra moléstias contagiosas, mas se constituía também em "factor de hygiene moral, impedindo que as creanças ouçam obcenidades, communs a taes individuos" (MELLO, 1917, p. 17). 
feminino prevalece o nervoso, predispondo a mulher a maior receptividade das impressões exteriores" (MELlo, 1917, p. 46).

Do ponto de vista da higiene física, as recomendações do autor, no que diz respeito à ginástica educadora, procuravam garantir às crianças de ambos os sexos ${ }^{14}$ o desenvolvimento harmônico das forças físicas e das faculdades intelectuais e morais, cuidando-se para que as aulas dessa disciplina não fossem desenvolvidas em horários próximos aos das refeições, nem tampouco nos intervalos destinados ao descanso ou ao recreio, superando-se, desse modo, aquilo que, em sua concepção, se constituía num "erro grave": o de supor que os males do excessivo esforço intelectual poderiam ser corrigidos pela atividade física. Como complemento da educação física, na formação do caráter da infância, a educação moral nos internatos deveria "incutir no espirito do alumno o culto da verdade, o despreso pelas más acções, a iniciativa e a energia de caracter, a rectidão de sua conducta, a comprehensão nitida das responsabilidades dos seus actos" (MELLO, 1917, p. 54). A educação física, intelectual e moral deveria, assim, primar pela formação de um indivíduo virtuoso, cumpridor dos seus deveres, útil e pronto para servir à sociedade e à pátria.

Um aspecto que chama a atenção, na análise da estrutura do livro Hygiene escolar e pedagogica, é o deslocamento da atenção das instalações escolares para o corpo do aluno, representado como objeto que deveria ser esquadrinhado, medido, pesado, sendo os dados produzidos, a partir dessas operações, registrados em fichas e sistematizados em tabelas - possibilitando os procedimentos de comparação e classificação. Deslocamento esse que não pode ser compreendido sem se levar em conta a difusão dos novos princípios científicos que passaram a orientar a prática médica, a partir do final do século XIX, e que responderiam pela elaboração de propostas cada vez mais amplas de intervenção sobre o universo escolar, as quais, extrapolando as ações de policiamento sanitário que caracterizavam as iniciativas de inspeção médica das escolas, procurariam atingir, de forma cada vez mais incisiva, o corpo das crianças. ${ }^{15}$

${ }^{14}$ Nas prescrições em relação à ginástica educadora, o corpo feminino figura cercado de uma série de cuidados, por meio dos quais se procurava evitar que a atividade física trouxesse danos à saúde, sobretudo quando desenvolvida durante o período menstrual.

${ }^{15}$ Como destaca Lima, referindo-se ao período entre 1900 e 1920, "a saúde escolar ou, mais propriamente, a higiene escolar da época, se deu na intersecção de três doutrinas: a da polícia médica, pela inspetoria das condições de saúde dos envolvidos com o ensino; a do sanitarismo, pela prescrição a respeito da salubridade dos locais de ensino; a da puericultura, pela difusão de regras de viver para professores e alunos e interferência em favor de uma pedagogia mais 'fisiológica', isto é, mais adequada aos corpos escolares aos quais se aplicasse" (LIMA, 1985, p. 85). 
$\mathrm{Na}$ estrutura da obra, essa inflexão se evidencia quando se observa que o autor reserva um espaço significativo para o tratamento da questão do exame: capítulo III - Exame medico do escolar, capítulo IV - Classificação dos anormaes e Capítulo VI - Médias do desenvolvimento physico dos escolares da cidade de $S$. Paulo. Em que pese a existência de um capítulo sobre as moléstias escolares, versando sobre aquelas que se adquirem e as que se propagam no meio escolar, no qual são reproduzidas algumas das informações presentes na obra publicada em 1902, é a questão do exame do escolar que assume um lugar central nesse livro. ${ }^{16}$

Considerando a exigência do exame físico cuidadoso de todos os alunos, do registro em fichas individuais e da classificação dos alunos em "normais" ou "anormais", instituída pela lei que reorganizou a IME, são apresentados, nesses três capítulos: modelo de ficha sanitária individual, ficha de exames anuais, esquema para classificação dos escolares, esquema para o exame clínico dos anormais e quadro do desenvolvimento físico dos escolares da cidade de São Paulo, os quais compõem, com a ficha de cadastro sanitário das escolas, inserida no primeiro capítulo, todo um conjunto de dispositivos produzidos pelo Dr. Vieira de Mello, na sua atuação à frente dessa repartição, e sistematizados de modo a guiar o trabalho dos médicos inspetores junto às escolas paulistas.

Dispositivo de produção de conhecimento sobre a infância, as fichas individuais reuniam dados de identificação, registros sobre a vacinação, revacinação e ocorrências mórbidas verificadas desde o nascimento da criança, dados resultantes do exame físico e observações pedagógicas, as quais deveriam ser fornecidas pela professora. Produzidas no entrecruzamento da autoridade dos médicos e dos professores, as fichas deveriam registrar os dados levantados a partir de um exaustivo exame físico que incidia sobre os mais diversos aspectos, que iam da aparência geral ao funcionamento dos órgãos, sem deixar de lado as mensurações antropométricas de estatura e peso, capacidade respiratória e força muscular. Exame esse que seria complementado

${ }^{16}$ Semelhante deslocamento pode ser observado na legislação, cabendo, nesse sentido, registrar que, dentre as atribuições que competiam aos médicos inspetores em relação aos estabelecimentos de ensino sob sua responsabilidade, figura em primeiro plano, na Lei n. 1.541: "examinar cuidadosamente os alumnos das varias classes de ensino, colligindo todos os dados que tiver obtido em vista do exame geral e organico de cada um, de modo a constituir as respectivas fichas; e, em razão dellas, classifical-os entre os alumnos normaes ou anormaes, especificando neste caso em que consistem as deficiencias observadas e qual o regimen especial que reclamam" (MELLO, 1917, p. 172). 
pelas observações pedagógicas, as quais se voltavam para a atenção, memória, inteligência e comportamento da criança.

Documento oficial da IME, concebido como instrumento que deveria guiar e conformar as práticas tanto dos médicos inspetores como das professoras, o livro publicado pelo Dr. Vieira de Mello em 1917 não apenas elenca os vários aspectos sobre os quais deveria repousar a atenção do examinador, mas expõe, minuciosamente, os procedimentos de exame, cumprindo a fotografia, ao longo desses capítulos, o papel de demonstração de tais procedimentos, como também de exemplificação das deformidades descritas, as quais poderiam ser evidenciadas por meio das práticas de exame. Com base nessa investigação, que não se restringia aos aspectos visíveis, mas buscava interrogar sobre as mais recônditas características humanas, as crianças eram classificadas em "normais" ou "anormais", ${ }^{17}$ conforme se aproximassem dos padrões de desenvolvimento físico e intelectual compatíveis com a sua idade.

O capítulo intitulado Classificação dos anormaes é marcado pelas orientações em relação à classificação do escolar mentalmente anormal e descrições que possibilitavam identificar os anormais intelectuais, morais e pedagógicos, seguidas de um esquema para o exame clínico e classificação dessas crianças, no qual são descritos os "estygmas de degenerescencia, ou anomalias physicas de caracter permanente" (MELLo, 1917, p. 105). Incidindo sobre vários dos itens que compõem a ficha sanitária individual, esse esquema, diferentemente das fichas, não deixava margens para o registro das características das crianças. Visando orientar a identificação das deformidades e o trabalho de classificação, o esquema se constitui numa espécie de catálogo das deformidades, que poderiam ser encontradas no exame das crianças consideradas anormais.

Quadros antropométricos registrando as médias de desenvolvimento dos escolares de 6 a 15 anos da cidade de São Paulo, por sexo, calculadas com base em dados sobre estatura, peso e perímetro torácico (capacidade respiratória), cuja relação expressava o "coeficiente de robustez física" - colhidos pelo Dr. Vieira de Mello, no período de 1912 a 1916, de um total de 17.263 crianças matriculadas em grupos escolares do centro e arrabaldes da cidade -, dão visibilidade às questões tematizadas no último capítulo do livro. Intitulado Médias do desenvolvimento physico dos escolares da cidade de São Paulo,

${ }^{17}$ A classificação pedagógica do escolar, calcada no critério da inteligência, dividia as crianças em: "supernormais ou precoces, normais, subnormais ou tardias", sendo que este último grupo compreendia: a) os astênicos, indiferentes, apáticos; b) os instáveis, irrequietos, impulsivos; c) os ciclotímicos (que apresentavam características das duas categorias anteriores). 
esse capítulo é marcado pelas preocupações em relação à constituição do denominado "tipo paulista".

É extremamente significativo, nesse sentido, o cuidado do autor na explicitação dos critérios que orientaram a escolha das escolas onde seriam realizadas as medições, os quais priorizaram aquelas onde predominava a população operária, na medida em que, segundo ele, não era objetivo da investigação exibir a robustez física do "tipo paulista". No horizonte das suas intenções estava a de "crear o 'typo' decorrente da caldeação de raças que se nota em tão larga escala nesta Capital e da sua distribuição por egual em quase todas as nossas escolas, onde as matriculas accusam um verdadeiro internacionalismo de progenitores dos escolares que as frequentam e a maior communhão das profissões que elles exercem" (MELLO, 1917, p. 153-154).

Interrogando sobre o "crescimento físico ou antropométrico", os estudos e as intervenções propostas pelo Dr. Vieira de Mello tinham como intento produzir o tipo físico considerado normal, com base no qual se constituíam também os quadros de anormalidades. Assim,

para se apreciar os desvios da média do desenvolvimento physico de uma creança, compara-se a sua estatura, o seu peso e a sua capacidade respiratoria com os de outra creança da mesma edade, afim de verificar si ella é egual, superior ou inferior, isto é, se as médias notadas são eguaes aos da sua edade, superiores ou inferiores. (MELLO, 1917, p. 165)

Instrumento a serviço da produção da identidade, mas também da diferença, a antropometria oferecia todo o seu arsenal de dispositivos para a constituição do público escolar e, ao mesmo tempo, para a distinção daqueles que necessitavam de um regime especial, na medida em que, pelas suas deformidades, não se conformavam às exigências da escolarização. Assim, a par dessas operações de esquadrinhamento do corpo infantil, vão sendo produzidos os parâmetros de normalidade, com base nos quais se poderia aquilatar quanto "vale physicamente" cada criança em comparação com os da sua idade. Média e desvios vão se articulando, desse modo, na produção do "tipo paulista" e, ao mesmo tempo, das figuras do subnormal e do supernormal.

Instituindo um conjunto de normas que deveriam orientar as práticas escolares, produzindo todo um conjunto de dispositivos voltados para o disciplinamento da infância e, ao mesmo tempo, constituindo um novo corpo profissional encarregado de pôr em prática essas normas e preceitos, os dois 
livros produzidos pelo Dr. Vieira de Mello, em diferentes momentos da sua cruzada em favor da vigilância higiênica da escola e da criança, se inserem no contexto das estratégias acionadas pelos médicos-higienistas, com vistas a configurar a escola em espaço de higienização e moralização. Estratégias essas que não podem ser lidas sem se ter em conta o amplo projeto de reforma social e moral, que tinha como principal alvo o controle da população.

Medindo e pesando as crianças, elaborando fichas e boletins nos quais eram registrados os resultados dessas mensurações, utilizados no estabelecimento de parâmetros de normalidade, a IME exerceu um papel fundamental na produção de um conhecimento científico sobre a infância, participando, de forma decisiva, na elaboração de dispositivos de normalização que tinham como horizonte a constituição de um tipo higiênica e eugenicamente normal. $\mathrm{Na}$ inflexão que desloca a atenção do edifício escolar e do mobiliário para o corpo e a inteligência da criança, emergem aspectos significativos para a compreensão da produção social da escola como espaço de socialização e disciplinamento da infância. A análise das duas obras produzidas pelo Dr. Vieira de Mello oferece, nesse sentido, elementos para a reflexão sobre aspectos significativos da cultura escolar. Aspectos esses constituídos na intersecção de uma pluralidade de saberes que postularam o poder da ciência na configuração de um novo modelo de organização escolar e de uma pluralidade de dispositivos que visaram conformar a escola a padrões de eficiência e racionalidade.

\section{REFERÊNCIAS}

LIMA, G. Z. Saúde escolar e educação. São Paulo: Cortez, 1985.

MELLO, B. V. A hygiene na escola. São Paulo: Typographia do Diario Official, 1902.

MELLO, B. V. Hygiene escolar e pedagogica para uso de medicos, educadores e estabelecimentos de ensino. São Paulo: Casa Vanorden, 1917.

ROCHA, H. H. P. Do exame da criança à produção do aluno: notas sobre o estudo científico da infância. Revista Pedagógica, ano 6, n. 13, jul./dez. 2004.

ROCHA, H. H. P.; GONDRA, J. G. A escola e a produção de sujeitos higienizados. Perspectiva, v. 20, n. 2, p. 493-512, jul./dez. 2002. 
. Estratégias de higienização da organização escolar: a questão do corpo (1852/ 1902). Boletín de la Sociedad Argentina de Historia de la Educación, n. 1, p. 33-39, 2000.

SILVA, A. C. G. Inspeção médica escolar em São Paulo (1911-1930): a escola como lugar de higiene e saúde. São Paulo, 2001. Dissertação (Mestrado em Educação: História, Política, Sociedade) - Pontifícia Universidade Católica de São Paulo.

Texto recebido em 16 fev. 2005

Texto aprovado em 29 mar. 2005 